\title{
Effect of addition of proteins on the production of amorphous sucrose powder through spray drying
}

\author{
B. Adhikari ${ }^{\mathrm{a}, *}$, T. Howes $^{\text {b }}{ }^{\text {, B.R. Bhandari }}{ }^{\text {c }}$, T.A.G. Langrish ${ }^{\mathrm{d}}$ \\ ${ }^{a}$ School of Science and Engineering, The University of Ballarat, Mount Helen, VIC, 3353, Australia \\ ${ }^{\mathrm{b}}$ School of Engineering, The University of Queensland, QLD, 4072, Australia \\ ' School of Land, Crop and Food Sciences, The University of Queensland, QLD 4072, Australia \\ ${ }^{\mathrm{d}}$ School of Chemical and Bimolecular Engineering, University of Sydney, NSW 2006, Australia
}

\section{A R T I C L E I N F O}

\section{Article history:}

Received 18 March 2008

Received in revised form 22 December 2008

Accepted 9 January 2009

\section{Keywords:}

Amorphous sucrose

Protein segregation

Glass transition

Spray drying

Stickiness

ESCA

\section{Introduction}

Icing sugar or confectioner's sugar is a finely ground sucrose commonly used in households to make icing or frosting and deco rations of baked goods. It is often lightly dusted onto cakes and chocolates to impart subtle decorations and additional sweetness. Industrially, it is produced with the principle aim of rapid dissolu tion rate (due to small particle size), less gritty or sandy feel in mouth. Commercially available icing sugars, in the majority of cases, are semi crystalline in nature and are manufactured by mill ing and grinding of crystalline sugars (Rowe et al., 2006). The amorphous fraction is generally found at the surface (Roth, 1977). Although commercial icing sugar consists of mainly sucrose, additives such as hydrocolloids including alginates, gum Arabic, carrangeenans, locust bean gum, guar gum, agar, pectin and gelatin (Svolos, 1971), corn and potato starches and modified starches (Ciz,

\footnotetext{
* Corresponding author. Tel.: +61 3 53279249; fax: +61 353279240 .

E-mail address: b.adhikari@ballarat.edu.au (B. Adhikari).
}

1973) are commonly used. Hard fat (hydrogenated coconut oil and cotton seed oil) and anti oxidants are also routinely added to pro vide storage stability, better flowability and visual appeal (Sapro nov et al., 1995). Although Krishnamurthy and Suryanarayanan (2006) have tested the addition of protein to sugar solutions in a wide range of concentrations during freeze drying, in order to sup press sugar crystallization, there is no information in literature if icing sugar in an amorphous form has been produced in greater amounts using spray drying.

In pharmaceutical industries, spray dried lactose is commonly used in directly compressed tablets and capsules as diluent to pre serve and encapsulate active drugs. It is in glassy amorphous state and is responsible for the improved compressibility of the capsules (Rowe et al., 2006). However, due to higher cost of the lactose material and its possible impact on the people who cannot tolerate lactose, there is a need of an alternative excipient for pharmaceu tical drugs. Sucrose, especially the confectioner's sugar is also used as diluent, coating and sweetening agent in these tablets and cap sules. However, the poor flow characteristics of icing sugar have 
prevented its greater use in direct compression blends (Rowe et al., 2006). If sucrose could be converted into an amorphous form with enhanced flow characteristics, it can be a viable alternative to amorphous lactose. Furthermore, the food industry is increasingly looking into producing ice cream and dessert mixes through spray drying. Vega et al. (2005) have carried out spray drying trials of model ice cream mixes using spray dryers. They have found that when the sucrose concentration was increased from $11.4 \%$ to $41.8 \%$ the yield (recovery) decreased from $60 \%$ to $40 \%$. This extent of loss in recovery can render the whole process economically non viable.

It is known that a sucrose solution cannot be converted into a powder form through spray drying and that high molecular weight drying aids such as maltodextrins have to be added for this pur pose. It has been shown that a sucrose:maltodextrin (DE6) ratio of 60:40, on a dry solids mass basis, has to be maintained in order to make this process economically feasible even at moderate dry ing conditions (inlet and outlet temperatures $130150{ }^{\circ} \mathrm{C}$ and $70^{\circ} \mathrm{C}$, respectively) (Truong et al., 2005). This level of additive addition alters the quality of the end product. However, it has been shown recently (Adhikari et al., 2007) that some proteins have very rapid film forming properties when subjected to drying air. These films resist the particle to particle cohesive stickiness as well as the particle to wall stickiness when their trajectory allows them to reach the dryer roof and the wall. The non sticky behaviour of the surface of the protein droplet was attributed to the formation of a glassy surface film.

The aims of this paper are two fold. Firstly, to study the efficacy of the proteins to overcome the stickiness of sucrose during spray drying. Secondly, to study if a very small amount of protein addi tion, namely $0.51 \%$ on a dry solids mass basis, is sufficient to over come the surface stickiness of sucrose droplets. We will explore the possibility of using proteins as 'smart' drying aids for spray drying.

\section{Materials and methods}

\subsection{Materials}

Sucrose with 99.5\% purity (Sigma Aldrich, Australia) was used as model sugar. Sodium caseinate (Na C) (ALATAL $\left.{ }^{\mathrm{TM}} 180\right)$ and hydrolyzed whey protein isolate (WPI) (ALATAL ${ }^{\mathrm{TM}}$ 817) were ob tained, courtesy of NZMP, New Zealand and used as received.

\subsection{Methods}

\subsubsection{Solution preparation}

The protein sugar solution was prepared by heating the solu tion to $50{ }^{\circ} \mathrm{C}$ and agitating with the aid of a magnetic stirrer. The protein was first dissolved by adding small amounts of the pre weighed sample at a time under constant stirring to avoid clump ing of the powders. The stirring was mild in order to avoid air entrainment. Once the protein was dissolved sucrose was added. The sucrose to protein ratio was maintained at 99.5:0.5 and 99.0:1.0 on a dry solids mass basis. The total solids fraction in the feed solution was fixed at $25 \%$ by weight. Thus, the nominal feed concentration of the protein in the solution was either $0.25 \%$ or $0.125 \% .1 \mathrm{~kg}$ solution batches were prepared. The inherent mois ture content in the protein samples was determined and compen sated for.

\subsubsection{Moisture determination}

The moisture content of the powder was determined through vacuum drying (Thermoline Scientific, Australia) at $70^{\circ} \mathrm{C}$ and 500 mbar for $24 \mathrm{~h}$ followed by cooling the samples to the room temperature in desiccators in the presence of an excess amount of silica gel. Duplicate or triplicate tests were carried out.

\subsubsection{Powder production}

Powder from the protein sugar solutions were produced using a pilot scale spray dryer (SL20, Saurin Company, Victoria, Australia) with a water evaporating capacity of $2 \mathrm{~kg} / \mathrm{h}$. The inlet and outlet temperatures were maintained at $170{ }^{\circ} \mathrm{C}$ and $70^{\circ} \mathrm{C}$, respectively. A twin fluid $0.7 \mathrm{~mm}$ diameter spray nozzle was used for this pur pose. The powders were collected from the cyclone, and in the case of sweeps, they were collected by lightly sweeping the inner dryer wall.

\subsubsection{Water activity}

Water activity of the powder samples was determined using an AquaLab 3TE Series (Decagon, USA) water activity meter. The tem perature was maintained at $24.5 \pm 0.1{ }^{\circ} \mathrm{C}$ during the tests. Dupli cate or triplicate tests were carried out.

\subsubsection{Particle size}

The volume mean diameter was chosen to express the particle size as this is one of the most commonly reported particle size in spray dried powders. Particle size ranges are expressed as the $10 \%$ volume based size to the $90 \%$ volume based size. The particle size and size distribution were measured using a Malvern Laser Diffraction Particle Size Analyzer with a $100 \mathrm{~mm}$ lens (Malvern Mastersizer B, Malvern Instruments Co., Worcestershire, UK). Iso propanol was used as a dispersing medium for all the powders. Gentle mechanical stirring was applied to ensure better dispersion and particle distribution. Triplicate measurements were taken.

\subsubsection{Surface stickiness and drying history}

Surface stickiness and drying kinetics of drying droplets of su crose, protein and maltodextrin droplets were determined, in situ, using a probe based tack testing instrument. Details of this instrument are given elsewhere (Adhikari et al., 2007). The test procedure is briefly presented as follows. The stainless steel probe was attached to the shaft of the captive type linear actuator which was driven by Intelligent Motion System driver. The contact diam eter of probes was $2.5 \mathrm{~mm}$. The droplet holder was made up of a Teflon solid cylinder (diameter $5 \mathrm{~mm}$ ) which was mechanically at tached to the weighing section of the precision load cell $( \pm 0.1 \mathrm{mg})$. The approach, contact and the withdrawal of the probe from the droplet surface were monitored with a digital video camera at tached with a stereomicroscope. During the test, the stepper motor is driven downwards until the probe made good contact with the droplet surface. The contact and withdrawal speed of the probe was maintained at $50 \mathrm{~mm} / \mathrm{min}$ in all the trials. Once contact is established, the motor is subsequently withdrawn. The variation in the tensile force over time was continuously recorded. The tem perature of the droplet was recorded by inserting micro thermo couples ( $T$ type, Omega Engineering USA) to the droplet centre. The tensile strength, a peak force during the separation process normalized by the probe area, is taken as measure of stickiness of the droplet surface. The moisture history of the droplet was monitored through parallel experiments by placing the droplets on the droplet holder and monitoring the mass loss over time.

\subsubsection{Glass rubber transition temperature $\left(T_{g-r}\right)$}

The determination of a glass transition temperature $\left(T_{\mathrm{g}}\right)$ of su gar protein system through differential scanning calorimetery (DSC) is difficult due to the fact that the change in specific heat capacity is small and the signal is usually masked in the thermo grams. It is also reported that since sugar protein is incompatible systems, the $T_{\mathrm{g}}$ of the system, measured by DSC is usually domi nated by the $T_{\mathrm{g}}$ of the sucrose component (Kalichevsky et al., 1993). 
The $T_{\mathrm{g}-\mathrm{r}}$, which usually corresponds to the endset $T_{\mathrm{g}}$ measure sed by DSC, is used here as an indicator of glass transition. A ther mo mechanical compression test (TMCT) device developed in the School of Land, Crop and Food Sciences, The University of Queens land, Australia, was used to measure the $T_{\mathrm{g}-\mathrm{r}}$ of the powders. This instrument measures the changes in particle bed compressibility caused by individual particle deformation, which can be linked to the $T_{\mathrm{g}-\mathrm{r}}$ of the bulk powders. The working principle, design, process optimization and application for food powders in details are given elsewhere (Boonyai et al., 2006; Shrestha et al., 2007a) and only a brief description is given here. The TMCT device consists of a thermally controlled sample cell made up of an aluminum block $(50 \times 50 \times 25 \mathrm{~mm})$ with a circularly engraved section $(37 \times 5 \mathrm{~mm})$ to hold the powder. Four heating elements were in serted within the sample holder and connected to a PID heater con troller. A RTD thermocouple was inserted at the centre of sample cell and connected to the PC for data acquisition. The sample holder was connected to a texture analyzer TA XT2 (Stable Microsystem, UK) fitted with a $35 \mathrm{~mm}$ cylindrical aluminum probe. Since the test is based on movement of the probe due to gradual heating of the powder, the thermal expansion of the sample holder has to be determined and compensated for. Maltodextrin (DE6) which has a high $T_{\mathrm{g}}\left(T_{\mathrm{g}}>200^{\circ} \mathrm{C}\right)$, high melting point, physically and chemically stable, and has characteristics of a typical food powder, was chosen for expansion correction. The test was carried out in relaxation mode (constant compressive load). A time of $300 \mathrm{~s}$ was allowed for the maltodextrin under the probe, at compression force of $50 \mathrm{~N}$, to be stabilized before thermal scan ning. The sample holder with maltodextrin was heat scanned from $25^{\circ} \mathrm{C}$ to $180^{\circ} \mathrm{C}$ at $30^{\circ} \mathrm{C} / \mathrm{min}$ and data were recorded (Blank value). When the test powders were heat scanned, at the glass transition temperature the powder becomes soft and rubbery causing the downward displacement of probe. The magnitude of expansion by the sample cell (Blank value) was subtracted from the displacement of probe during thermal compression of sample to get the corrected data. The glass rubber transition temperature $\left(T_{\mathrm{g}-\mathrm{r}}\right)$ was determined by performing linear regression of corrected data. Linear regression was carried out at data points at the linear regions below and above the glass rubber transition temperature (regions $\mathrm{A}$ to $\mathrm{B}$, and $\mathrm{C}$ to $\mathrm{D}$ ) and extrapolated. The intersection of these two lines is taken as the $T_{\mathrm{g}-\mathrm{r}}$ point. The procedure to obtain the $T_{\mathrm{g}-\mathrm{r}}$ has been improved by applying an algorithm outlined in Appendix A which removes the need to manually constructing two lines.

\subsubsection{Electron spectroscopy for chemical analysis (ESCA)}

Electron spectroscopy for chemical analysis (ESCA) measure ments for sucrose, Na C and WPI were carried out to determine the surface composition of these materials. It is assumed that the surface elemental composition of pure materials is the same as its bulk elemental composition. Subsequently, the surface elemen tal composition of all the spray dried powders was determined. Prior to subjecting to the ESCA test, the samples were outgassed for $72 \mathrm{~h}$. The ESCA was performed on a Kratos AXIS Ultra with a $150 \mathrm{~W}$ monochromatic A1 X ray source. Each analysis started with a survey scan from 0 to $1200 \mathrm{eV}$ with a residence time of $100 \mathrm{~ms}$, pass energy of $160 \mathrm{eV}$ at steps of $1 \mathrm{eV}$, with a one sweep. For the high resolution analysis, the number of sweeps was increased, the pass energy was lowered to $20 \mathrm{eV}$, at steps of $50 \mathrm{meV}$ and the residence time was increased to $250 \mathrm{~ms}$. Data were acquired using a Kratos Axis ULTRA X ray spectrometer, incorporating a $165 \mathrm{~mm}$ hemispherical electron energy analyzer. The incident radiation was Monochromatic A1 X rays $(1486.6 \mathrm{eV})$ at $225 \mathrm{~W}$ $(15 \mathrm{kV}, 15 \mathrm{~mA})$. Survey (wide) scans were at analyzer pass energy of $160 \mathrm{eV}$. The base pressure in the analyser chamber was $10{ }^{9}$ Torr and during sample analyses it was maintained at $10{ }^{8}$ Torr.
ESCA was applied to measure the relative atomic concentration of carbon, nitrogen, oxygen, sulphur and sodium in the samples. The elemental composition of sucrose and $\mathrm{Na} \mathrm{C}$ obtained through ESCA were close to their theoretical composition. The experimental elemental composition of WPI was assumed to be within $10 \%$ of its theoretical value. A numerical method based on matrix inversion is available to determine the surface coverage of individual compo nents based on the ESCA data (Faldt et al., 1993; Kim et al., 2002; Shrestha et al., 2007b). However, as nitrogen is not present in sucrose, the protein surface coverage could be calculated from a simple nitrogen balance.

\subsection{9. $X$ ray diffraction}

XRD investigations were carried out on a Philips (Philips PW1840) X ray generator with $30 \mathrm{kV}$ accelerating voltage and $30 \mathrm{~mA}$ current. CoK $\alpha_{1}$ radiation was used. A variable divergence slit was used giving an irradiated area with a diameter of $20 \mathrm{~mm}$. An anti scatter slit of $0.6 \mathrm{~mm}$ and a detector slit of $0.2 \mathrm{~mm}$ was em ployed. Diffractograms were taken between 0 and $100^{\circ}(2 \theta)$ at a rate of $1^{\circ} / \mathrm{min}(2 \theta)$ and with a step size of $0.1^{\circ}(2 \theta)$. Diffractograms of sucrose protein powders and also that of icing sugar were ob tained and compared.

\subsubsection{Surface tension}

All surface tension measurements of the solutions were carried out with the Sinterface PAT 1 (Sinterface Technologies, Germany). Two different modes of tests, i.e., bubble in droplet and droplet in air were used. Sucrose and sodium caseinate formed clear solu tions; hence, the bubble in droplet method was used. Solutions containing WPI formed opaque or murky solutions and hence the droplet in air method was used. For the former method, distilled water was poured into the cuvette, and the settings of the tensiom eter were adjusted to ensure that the surface tension of water re mained within the range of $72.573 .0 \mathrm{mN} / \mathrm{m}$. Subsequently, air was pumped into the water to generate a small bubble. The camera was then adjusted to focus on the droplet. Once these adjustments were made, the water was poured out and the cuvette was dried. Subsequently, the test solution was poured in. $8 \mathrm{~mm}^{3}$ of solution was used for each run. Bubbles with $30 \mathrm{~mm}^{2}$ surface area were generated and surface tension values were noted. After the surface tension measurement, an area oscillation function, usually 19 $21 \mathrm{~mm}^{2}$ was used. The oscillation protocol was holding $(10 \mathrm{~s})$ oscillation (60 s) holding (10 s) in sequence. Surface tension values were measured at $45 \mathrm{~min}$ by best fitting bubble shapes with the Young Laplace equation. The cuvette was cleaned and dried before commencing the next run.

For the droplet in air, a pendant method was used. Distilled water (MilliQ) was used to clean the tubes and the syringe fol lowed by compressed air to dry the passage. The solution was pumped for a few minutes to purge the passage. A droplet with a surface area of $30 \mathrm{~mm}^{2}(15.45 \mu \mathrm{l})$ was generated at the tip of the needle. The remainder of the experiment procedure was of the same as the bubble in droplet process. The passage was cleaned and dried using water and compressed air before commencing the next run. Surface property data presented in this paper were obtained at $45 \mathrm{~min}$ after bubbles and droplets were created.

\section{Results and discussions}

\subsection{Powder recovery}

The sucrose Na C and sucrose WPI powders were collected from spray drying trials. Powders were recovered from the collec tion cyclone. Powders were also collected from within the dryer chamber by lightly sweeping it. The recovery was calculated as 
the ratio of the mass of solids collected to the solid mass in feed solution, both on a dry basis. Table 1 provides the recovery of these powders. These data are plotted and presented in Fig. 1. The mois ture content, equilibrium relative humidity (described as a water activity, $a_{\mathrm{w}}$ ) and the mean particle size of these powders are pro vided in Table 2 . The water activity and moisture content and par ticle size of these powders were measured quickly after collection, once adequate time was provided to bring the powder temperature down to room temperature. The powders were immediately sealed in the measuring cap to stop subsequent moisture uptake. It can be seen from Table 2 that the highest moisture content and $a_{\mathrm{w}}$ are $2.78 \%$ and $0.24 \%$, respectively. Furthermore, the majority of water activity values are around 0.20 . These values fall within commonly observed moisture and $a_{\mathrm{w}}$ values in industrial spray drying.

Table 1 and Fig. 1 show that the total recovery of sucrose with out addition of protein is about $18 \%$ and that no powder was recov ered from the cyclone. Powders recovered from the sweep were also fully crystallized. This may be due to the fact that the semi dried sucrose wall deposits crystallized during the cooling stage of the process following spraying. As these powders were not any closer to normal spray dried powders, the powder recovery even at this mild spray drying condition, can be taken as zero. From this observation, it can be stated that it is not possible to convert sucrose droplets into amorphous powder through spray drying, at least at inlet and outlet temperatures of $160^{\circ} \mathrm{C}$ and $70^{\circ} \mathrm{C}$, respectively. This result agrees with previous observations that no powders were recovered from spray drying trials of sucrose in similar drying conditions (Truong et al., 2005).

When $0.5 \%$ of sucrose solid was replaced with Na C and WPI the total recovery rose to $81 \%$ in both cases. The cyclone recovery, which is an in indicator of spray drying success (Bhandari et al.,

Table 1

Powder recovery of sucrose-Na-C and sucrose-WPI powders in spray drying trials (Inlet $=160^{\circ} \mathrm{C}$ and outlet $-70^{\circ} \mathrm{C}$ ).

\begin{tabular}{llll}
\hline Powder recovery (\%) & Cyclone & Sweep & Total \\
\hline Sucrose & $0 \pm 0.00$ & $18.1 \pm 0.72$ & $18.1 \pm 0.72$ \\
Sucrose:Na-C (99.0:1.0) & $67.24 \pm 2.42$ & $13.79 \pm 0.88$ & $81.03 \pm 3.31$ \\
Sucrose:Na-C (99.5:0.5) & $64.79 \pm 1.51$ & $15.88 \pm 3.22$ & $80.67 \pm 4.73$ \\
Sucrose:WPI (99.0:1.0) & $61.51 \pm 0.7$ & $23.29 \pm 0.61$ & $84.80 \pm 3.31$ \\
Sucrose:WPI (99.5:0.5) & $60.26 \pm 0.94$ & $20.67 \pm 0.94$ & $80.93 \pm 1.88$ \\
\hline
\end{tabular}

1997), was greater than $60 \%$ for both the sucrose Na C and su crose WPI powders. As greater than $50 \%$ recovery in the cyclone has been considered to be a good criteria for successful drying (Bhandari et al., 1997), the addition of addition of $0.125 \%$ protein to the feed has made it possible to spray dry sucrose solutions, which otherwise was not possible without the addition of large amounts of maltodextrin additives. When $1 \%$ of the sucrose was re placed by Na C and WPI in the feed, the recoveries are not much greater than for the lower amounts of protein. Proteins preferen tially migrate to the air water interface of sugar solutions and form a protein rich film there. When this film is subjected to hot and dry air, it is converted into a glassy skin which grows in thick ness as the drying progresses. This skin was found to withstand greater than $10 \mathrm{kPa}$ of compressive pressure (Adhikari et al., 2007). Hence, the greatly enhanced powder recovery with the addition of $0.125 \%$ of protein in solution indicates that this film can successfully resist the coalescence of droplets as well sticky interactions with the dryer wall. From these identical powder recoveries, it can be stated that both the Na C and WPI are equally capable of overcoming the particle wall stickiness.

From Table 2 it can be seen that the mean particle size of sucro se:Na C is twice as large as sucrose WPI particles. However, the particles of sucrose:protein (99.5:0.5) are not much bigger com pared to those of sucrose:protein (99.0:1.0). This corroborates to the very close powder recovery of these two formulations. The par ticle size data also confirm that in this particle size range losses due to fines has much less influence here, this is because the su crose Na $\mathrm{C}$ powders are twice as large compared to sucrose WPI particles.

$\mathrm{X}$ ray diffraction profiles of icing sugar (CSR Sugar Company, Australia) and sucrose protein powder, from this study, are pre sented in Fig. 2. This figure shows that while the icing sugar, even though it had a mean particle diameter of $32.62 \mu \mathrm{m}$ (and size range $10.7678 .49 \mu \mathrm{m}$ ), it is still completely crystalline. On the other hand, as shown from this figure, both the sucrose Na C and su crose WPI powders are completely amorphous. This is of great sig nificance that the addition of mere $0.5 \%$ proteins, on a dry solid basis, can completely change the nature of the resultant spray dried sucrose powder. This indicates that these powders could be most suitable for use as a diluent of pharmaceutical drugs in hot pressed tablet/capsule production.

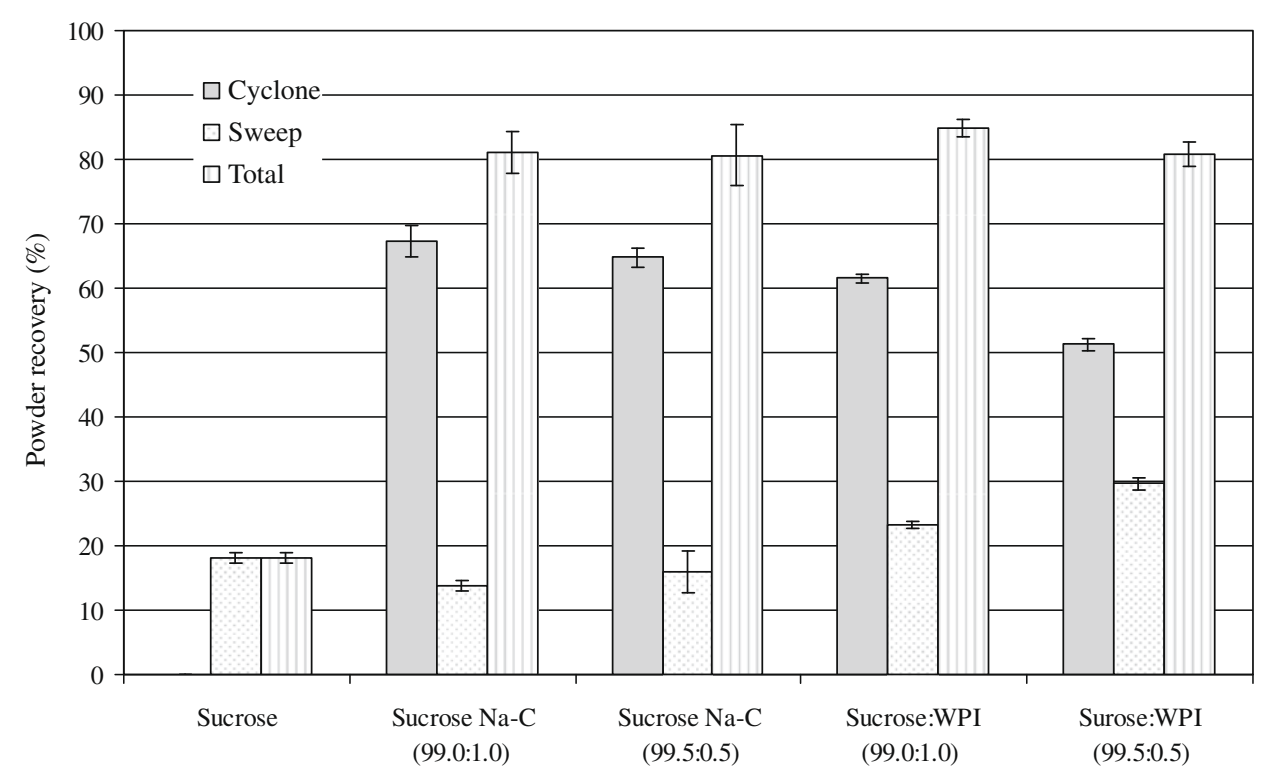

Fig. 1. Recovery of spray dried sucrose-Na-C and sucrose-WPI powders in spray drying trials (inlet $=160{ }^{\circ} \mathrm{C}$, outlet $=70{ }^{\circ} \mathrm{C}$ ). 
Table 2

Moisture content, water activity $\left(a_{\mathrm{w}}\right)$ and mean particle size of sucrose-Na-C and sucrose-WPI powders obtained from spray drying trials (inlet $=160{ }^{\circ} \mathrm{C}$ and outlet $=70{ }^{\circ} \mathrm{C}$ ).

\begin{tabular}{llll}
\hline Samples & Moisture content $(\%, \mathrm{db})$ & Water activity $\left(\right.$ at $\left.24.5 \pm 0.1{ }^{\circ} \mathrm{C}\right)$ & - \\
\hline Na-C (as received) & $6.00 \pm 0.01$ & - & $86.34 \pm 6.67$ \\
WPI (as received) & $6.67 \pm 0.15$ & $0.214 \pm 0.001$ & $36.67 \pm 3.43$ \\
Sucrose:Na-C (99.0:1.0) & $2.6 \pm 0.09$ & $0.214 \pm 0.001$ & $44.17 \pm 3.09$ \\
Sucrose:Na-C 99.5:0.5) & $2.78 \pm 0.1$ & $0.187 \pm 0.001$ & $40.39 \pm 5.07$ \\
Sucrose:WPI (99.0:1.0) & $1.98 \pm 0.04$ & $0.240 \pm 0.002$ & $18.9 \pm 7.23$ \\
Sucrose:WPI (99.5:0.5) & $2.12 \pm 0.11$ & $15 \pm 6.59$ \\
\hline
\end{tabular}
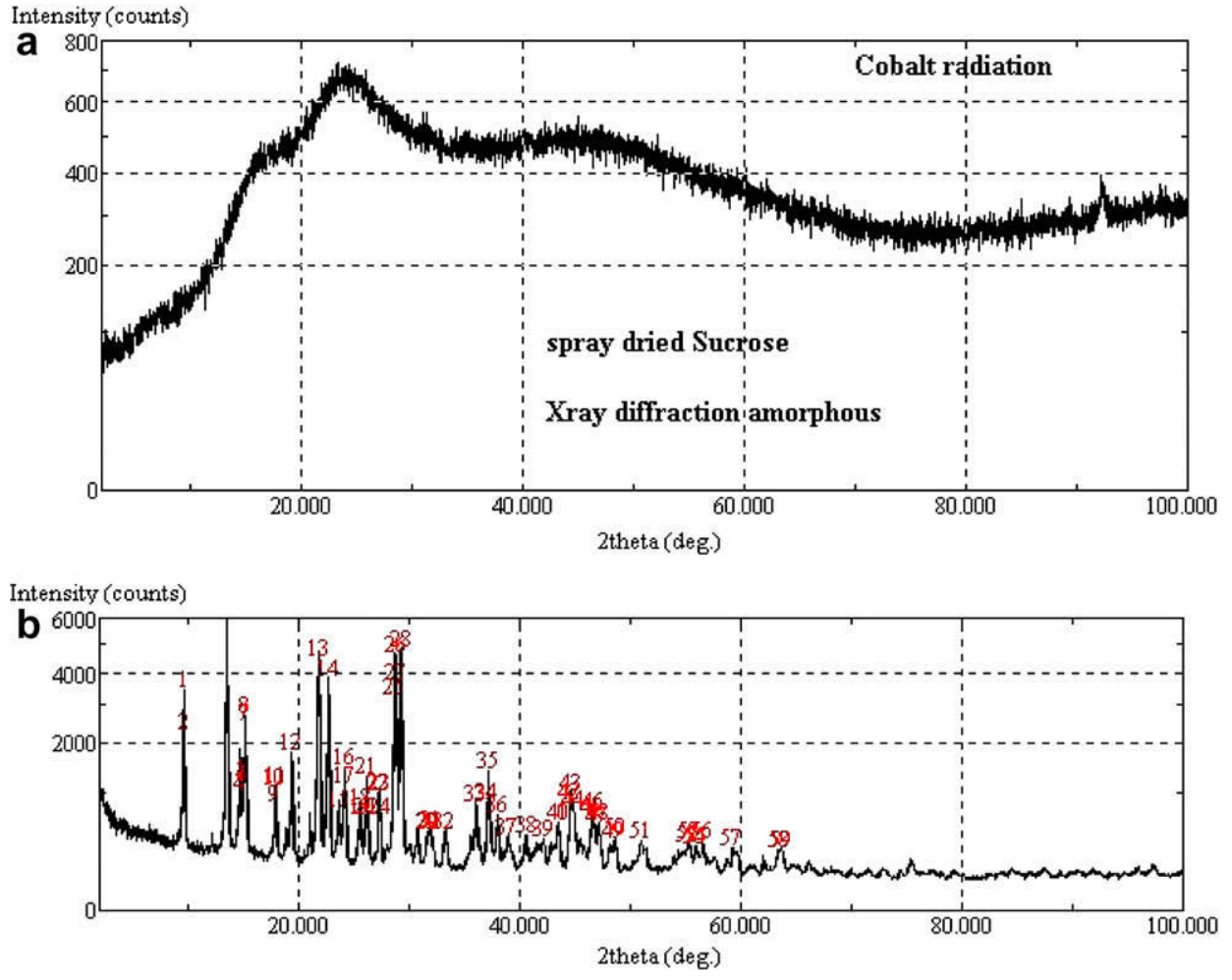

Fig. 2. X-ray diffraction pattern of (a) sucrose:Na-C and (b) icing sugar (CSR Company, Australia).

\subsection{Mechanism of sugar protein matrix during particle formation}

The dramatic effect of a small amount of protein $(0.51 \%$ on dry mix) on sucrose droplets during spray drying requires some discus sion and further explanations. This effect is an integral expression of two entirely different phenomena, firstly, the preferential migra tion of proteins (or segregation) and, secondly, the film forming nature of the protein when brought into contact with hot and dry air. These two effects will be discussed in the ensuing sections with the aid of surface tension, ESCA and surface stickiness experiments.

\subsubsection{Surface activity and migration of protein in sucrose protein solutions}

The surface tension values of sucrose Na C and sucrose WPI solutions are presented in Fig. 3. Surface tension values of sucrose, $\mathrm{Na} \mathrm{C}$ and WPI solutions are given as reference. It can be seen from this figure that the surface tension value of $25 \%$ sucrose solution is $73.9 \mathrm{mN} / \mathrm{m}$, which is close to the literature value (Weast, 1988). The surface tension values of both Na C and WPI in the concentra tion range of $0.125 \%$ and $0.25 \%$ are in the range of $4045 \mathrm{mN} / \mathrm{m}$. This is slightly below the equilibrium surface tension value of $47 \mathrm{mN} / \mathrm{m}$ for many proteins reported in literature (Bos and van Vliet, 2001). However, since $47 \mathrm{mN} / \mathrm{m}$ is the mean of surface tension values for many proteins, our data are reasonably close to this value. This also indicates that the proteins have had suffi cient time to migrate to the droplet air interface or the droplet sur face. Furthermore, the surface tension values of sucrose $\mathrm{Na} C$ and sucrose WPI solutions are close to the surface tension values of the corresponding protein concentrations indicating that the sucrose molecules have little or no effect at this level of protein concentra tion. It can be seen from this figure that the surface tension values of Na C and WPI solutions are very close to each other, albeit that of $\mathrm{Na} \mathrm{C}$ are slightly lower.

As the sucrose molecules are not responsible for lowering of the surface tension of sucrose protein solutions, the migration of pro tein molecules is responsible for the subsequent lowering of the surface tension of the solutions. The proteins being surface ac tive preferentially migrate to the air water interface. When the solution reaches an equilibrium surface tension, the surface of the droplet reaches equilibrium in terms of protein surface cover age. Although the molecular size of the proteins decide how fast they can diffuse to the air water interface, looking from the pow der recovery data, it appears that the time is sufficient for both the $\mathrm{Na} C$ and WPI molecules to diffuse to the air water interface. It can be stated here that the surface active nature of proteins, due to their surface tension, is the driving force for them to diffuse to the air water interface. Hence, when droplets are formed during 


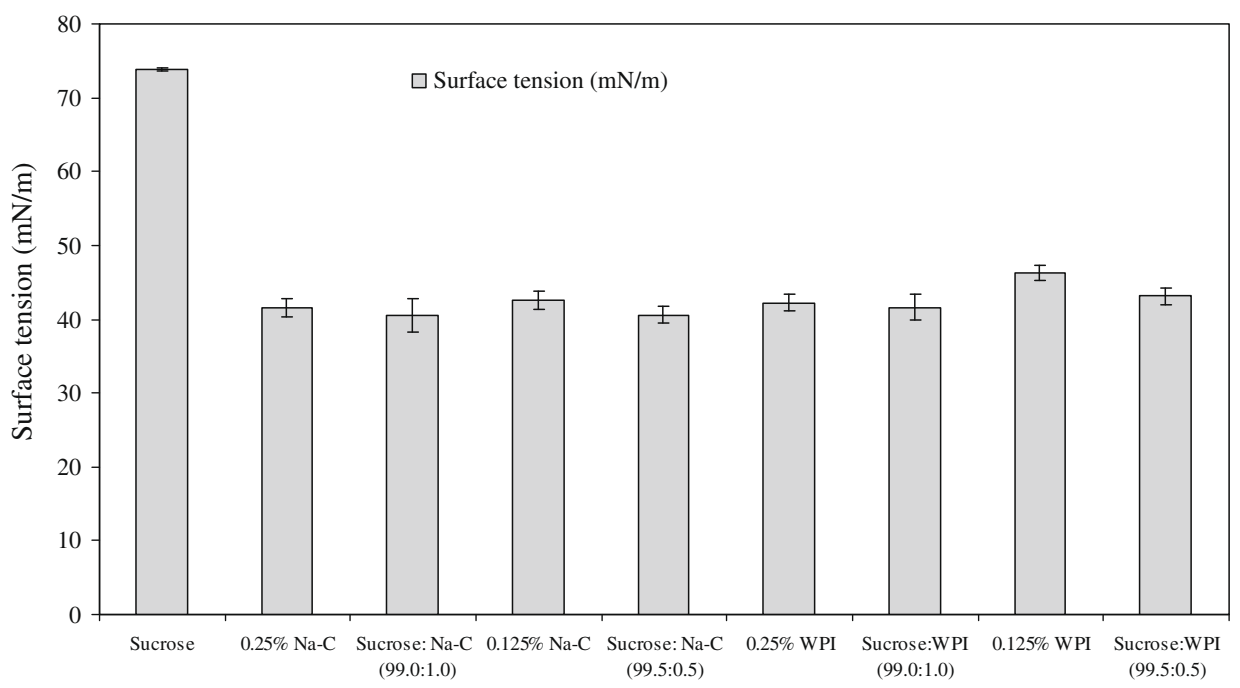

Fig. 3. Surface tension $(\mathrm{mN} / \mathrm{m})$ of sucrose-Na-C and sucrose-WPI solutions.

atomization, it is possible that the proteins are already at the air water interface of the droplet. In addition, Tarasov et al. (2006) have shown that the spreading velocity of proteins on surfaces is relatively high $\left(0.2 \mathrm{~m} \mathrm{~s}^{1}\right)$ compared with the size of the particles (typically $80 \mu \mathrm{m}$ ). Even though the fresh surface will be generated at the point of atomization, and initially will have a protein con centration equal to the bulk concentration, this fresh surface will very quickly attract protein. Given their low diffusivity, their sur face coverage can be attributed to the fact that the solution surface is already reached equilibrium and that the protein film simply gets transferred when new surface is created during atomization. Whatever is the case, segregation of protein and its occupation of the droplet surface is responsible for overcoming the stickiness of protein droplets during spray drying.

The extent of migration of protein to the air water interface can be quantified using the ESCA data of the spray dried powders. The elemental composition of carbon, oxygen and nitrogen at the sur face of the sucrose protein particles is presented in Table 3. The elemental compositions of Sucrose, Na C, WPI are presented as a reference. It can be seen from this table that that 55.76\% (expressed as a mass fraction) of the surface of sucrose $\mathrm{Na} C$ particle is cov ered by $\mathrm{Na} \mathrm{C}$ whereas the mean feed concentration of this protein was only $1 \%$ on a dry solid basis. As can be seen from Table 1 , this level of surface coverage successfully increased the powder recov ery from zero to $81 \%$. Similarly $1 \%$ WPI in the bulk feed has resulted in $58 \%$ surface coverage of sucrose WPI particle and that this led to $85 \%$ total powder recovery. This extent of surface coverage has be come possible due to preferential migration of proteins at the air water interface.

When the sucrose:protein solid ratio in the feed was main tained at 99.5:0.5, (nominal protein concentration in feed $=$ $0.125 \%$ ) it can be seen that the protein surface coverage was almost identical to that of with 99:1. This implied that, where the protein coverage is concerned, the droplet surface has already reached sat uration and that no more protein molecules were able to occupy the surface even if the protein concentration in the bulk is in creased. The fact that $0.125 \%$ nominal protein concentration in droplet can attain equilibrium in terms of their surface coverage will have profound implication in using these proteins as 'drying aids'. In fact, as low as $0.125 \%$ nominal protein composition in the feed appears to be sufficient to attain close to maximal protein coverage at the particle surface.

\subsubsection{Formation of non sticky protein rich film during drying}

The evolution of surface stickiness or tack for sucrose water, WPI water and maltodextrin (DE6) water at $70 \pm 1{ }^{\circ} \mathrm{C}, 2.5 \pm 0.5 \%$ relative humidity is presented in Fig. 4 . The data for maltodextrins is presented here as this is the most widely used drying aid to over come the stickiness of sugar rich foods, including sucrose.

The repeatability of the measurements, based on standard devi ation, is shown through error bars. This varied between $5 \%$ and $8 \%$ of the measured mean values. The peak tensile strength of WPI droplets on stainless steel surfaces were achieved at $u=2.2$ ( $u=$ average moisture on a dry solids basis) In the case of malto dextrin, the peak tensile pressure occurred at $u=0.98$ which is much lower compared to that of WPI. At this point a clean adhesive failure occurred for both the materials when the probe was pulled away. This is because at those moisture contents the tensile strength of the droplet surface is close enough to achieve the adhe sive strength at droplet probe interface. The WPI droplet surface attained a complete non sticky state when the average moisture was $u=1.27$ and the corresponding drop temperature and drying time was $54.3{ }^{\circ} \mathrm{C}$ and $710 \mathrm{~min}$. For maltodextrins the non sticky state was reached at the much lower moisture content of

Table 3

Surface composition of spray dried sucrose-Na-C and sucrose-WPI powders.

\begin{tabular}{|c|c|c|c|c|}
\hline Samples & Carbon (\%) & Oxygen (\%) & Nitrogen (\%) & Protein on surface (\%) \\
\hline Sucrose & $53.66 \pm 2.37$ & $46.34 \pm 2.37$ & $0.00 \pm 0.00$ & - \\
\hline Sodium caseinate & $67.87 \pm 0.42$ & $16.87 \pm 0.31$ & $14.92 \pm 0.59$ & - \\
\hline Sucrose:Na-C (99.0:1.0) & $62.98 \pm 0.01$ & $28.52 \pm 0.14$ & $8.32 \pm 0.36$ & $55.76 \pm 4.33$ \\
\hline Sucrose:Na-C (99.5:0.5) & $63.82 \pm 0.03$ & $28.84 \pm 0.17$ & $7.34 \pm 0.20$ & $50.51 \pm 2.72$ \\
\hline WPI & $71.94 \pm 0.58$ & $17.10 \pm 0.38$ & $10.28 \pm 0.05$ & - \\
\hline Sucrose:WPI (99.0:1.0) & $58.17 \pm 1.52$ & $35.66 \pm 1.28$ & $6.01 \pm 0.39$ & $58.46 \pm 6.49$ \\
\hline Sucrose:WPI (99.5:0.5) & $58.15 \pm 0.42$ & $35.85 \pm 0.56$ & $5.81 \pm 0.44$ & $56.52 \pm 7.57$ \\
\hline
\end{tabular}




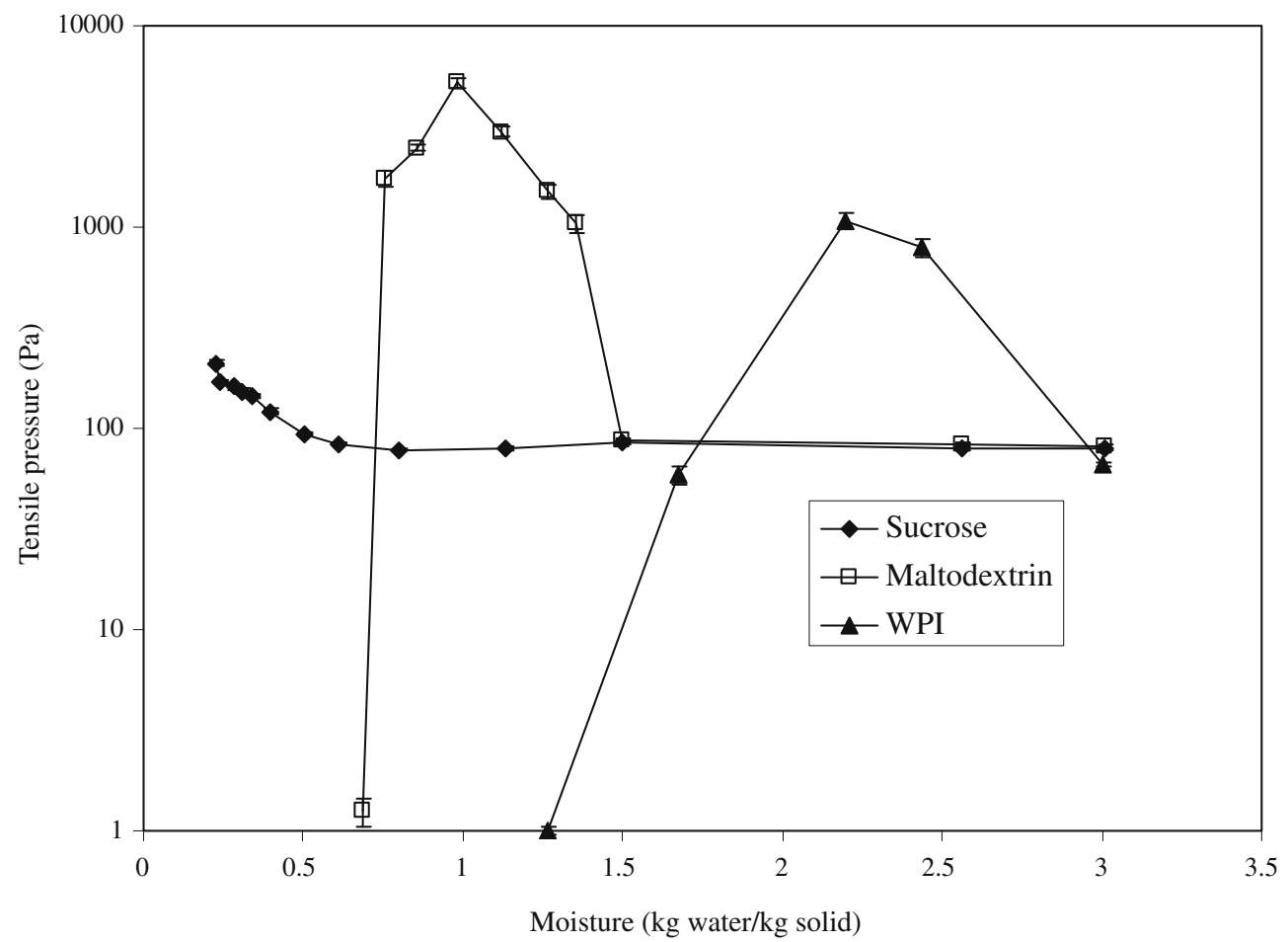

Fig. 4. Moisture content ( $\mathrm{kg}$ water $/ \mathrm{kg}$ solid) versus tensile pressure of sucrose, maltodextrins (DE6) and WPI at $70 \pm 1{ }^{\circ} \mathrm{C}, 2.5 \%$ relative humidity and $50 \mathrm{~mm} / \mathrm{min}$ probe withdrawal speed.

$u=0.69$. At this point, we applied $10 \mathrm{kPa}$ of compressive pressure at the droplet surface to make sure that the surface was non sticky. It was further observed that that a smooth non sticky skin was formed on the surface of WPI film immediately when it was sub jected to drying air which behaved like non sticky plastic pouch. In the case of maltodextrins, although skin formation was observed almost at the same time compared with WPI, it took a longer time for this skin to develop into a much thicker shell. The WPI film con verted into glassy film much earlier compared to the maltodextrin shell. This explains why WPI and Na C are much more effective drying aids compared to maltodextrin. In the case of sucrose drop let there is no visible skin formation, and hence the Fig. 4 shows that its surface was always sticky at the prevailing condition.

\subsubsection{The glass rubber transition of sucrose protein powders}

The Glass transition temperature $\left(T_{\mathrm{g}}\right)$ of a spray dried powder can be used as an indicator to assess if a droplet or particle is likely to stick to the spray dryer wall. A practical rule is that if the drop let/powder temperature is $20^{\circ} \mathrm{C}$ above its $T_{\mathrm{g}}$, it will be sticky (Roos, 1993). $T_{\mathrm{g}}$ is a strong function of moisture content, and generally the mean moisture content is used to calculate it. As the $T_{\mathrm{g}}$ of protein sugar mixture is not easily determined using DSC, we have used TMCT to determine $T_{\mathrm{g}-\mathrm{r}}$, which is usually very close to endset $T_{\mathrm{g}}$, measured by a DSC (Boonyai et al., 2006). A typical plot (for anhy drous sucrose:Na C (99.0:1.0) powder) that provides the $T_{\mathrm{g}-\mathrm{r}}$ val ues from the displacement versus temperature plot is presented in Fig. 5. The intersection of two straight lines, one representing

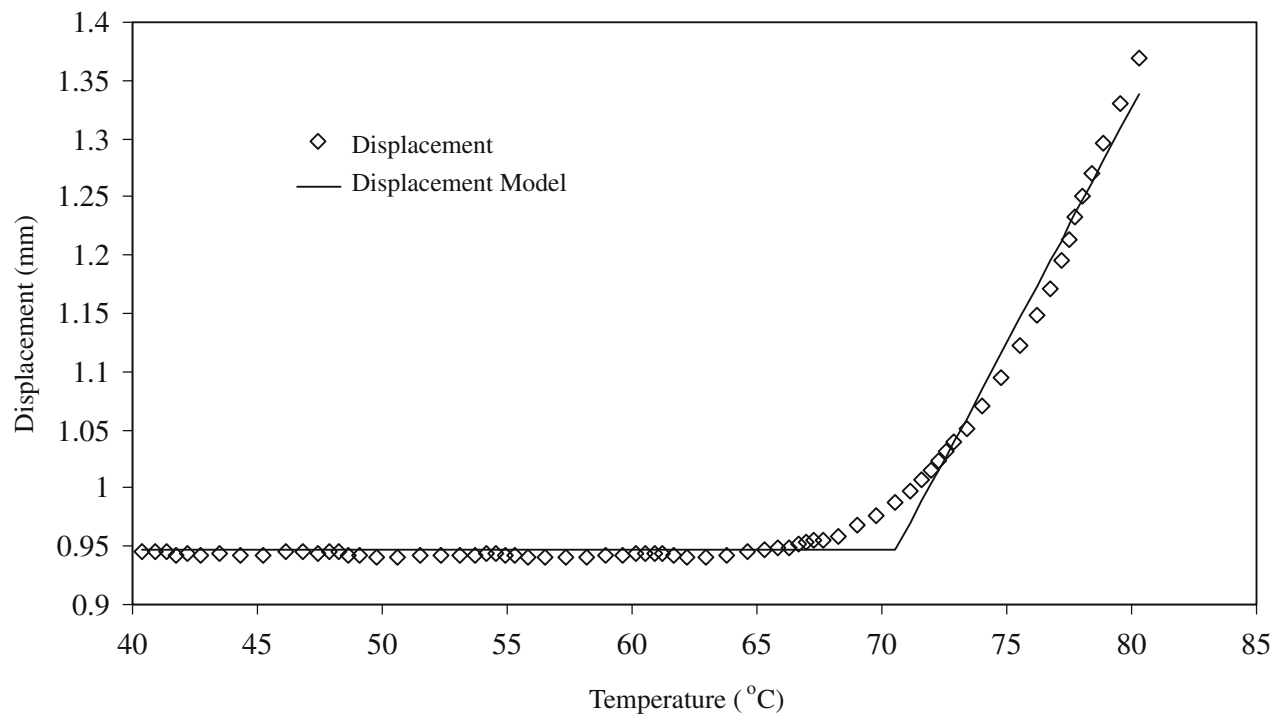

Fig. 5. The temperature versus probe displacement plots for anhydrous sucrose: Na-C at (99.5:0.5) and (99.0:1.0) compositions. 
data points below $T_{\mathrm{g}-\mathrm{r}}$ and one above $T_{\mathrm{g}-\mathrm{r}}$ provides $T_{\mathrm{g}-\mathrm{r}}$ value for a sample. An algorithm is developed (Appendix A) to track this inter section. It can be seen from Fig. 5 that the algorithm is able to fit the data reasonably well and locate the intersection point or the $T_{\mathrm{g}-\mathrm{r}}$ values.

The TMCT plots for anhydrous sucrose:Na $C$ powders at ratios of (99.5:0.5) and (99:1) are presented in Fig. 6. It can be seen from this figure that, so long the powder is below the $T_{\mathrm{g}-\mathrm{r}}$, thee is no downward displacement of the probe. This is because below $T_{\mathrm{g}-\mathrm{r}}$ the powder is glassy and that it is not soft enough to allow the probe to move downward. Hence, below $T_{\mathrm{g}-\mathrm{r}}$, the powder bed is able to maintain its initial thickness and resist flow due to constant compressive force. When the temperature reaches or crosses $T_{\mathrm{g}-\mathrm{r}}$, the powder softens progressively which allows the downward movement of the probe. The linear increase in the probe displace ment is due to the fact that the power bed is unable to maintain its thickness due to its progressive softening above $T_{\mathrm{g}-\mathrm{r}}$. From this fig ure, it can also be seen that the $T_{\mathrm{g}-\mathrm{r}}$ of the sucrose:Na $\mathrm{C}(99: 1)$ powder is $71^{\circ} \mathrm{C}$ which is $1{ }^{\circ} \mathrm{C}$ above the $T_{\text {g-r }}$ of sucrose:Na C (99.5:0.5) powder. Vega and Roos (2007) reported the $T_{\mathrm{g}}$ of anhy drous sucrose:Na $\mathrm{C}(6: 1)$ and sucrose to be $70.1^{\circ} \mathrm{C}$ and $69^{\circ} \mathrm{C}$, respectively. These data corroborate well with previous findings that sugar protein systems are not compatible and that the measured $T_{\mathrm{g}}$ mainly reflects the $T_{\mathrm{g}}$ of the sugar in the system (Kalichevsky et al., 1993). For the anhydrous sucrose WPI powders (Table 4) the $T_{\mathrm{g}-\mathrm{r}}$ is $66{ }^{\circ} \mathrm{C}$ and $67^{\circ} \mathrm{C}$ when WPI constituted $0.5 \%$ and $1 \%$ of the dry powder. These data are close to the $T_{g}$ of sucrose (Table 4). This further confirms that the overall $T_{\mathrm{g}}$ of the sucrose WPI powders is dominated by the $T_{\mathrm{g}}$ of the sucrose. This is reasonable because sucrose comprises greater than $99 \%$ of the dry solid in the test powders.

Recently, Haque and Roos (Haque and Roos, 2006; Haque and Roos, 2004) conducted a series of studies to find out the effect of protein on sugar protein systems obtained from both freeze dry

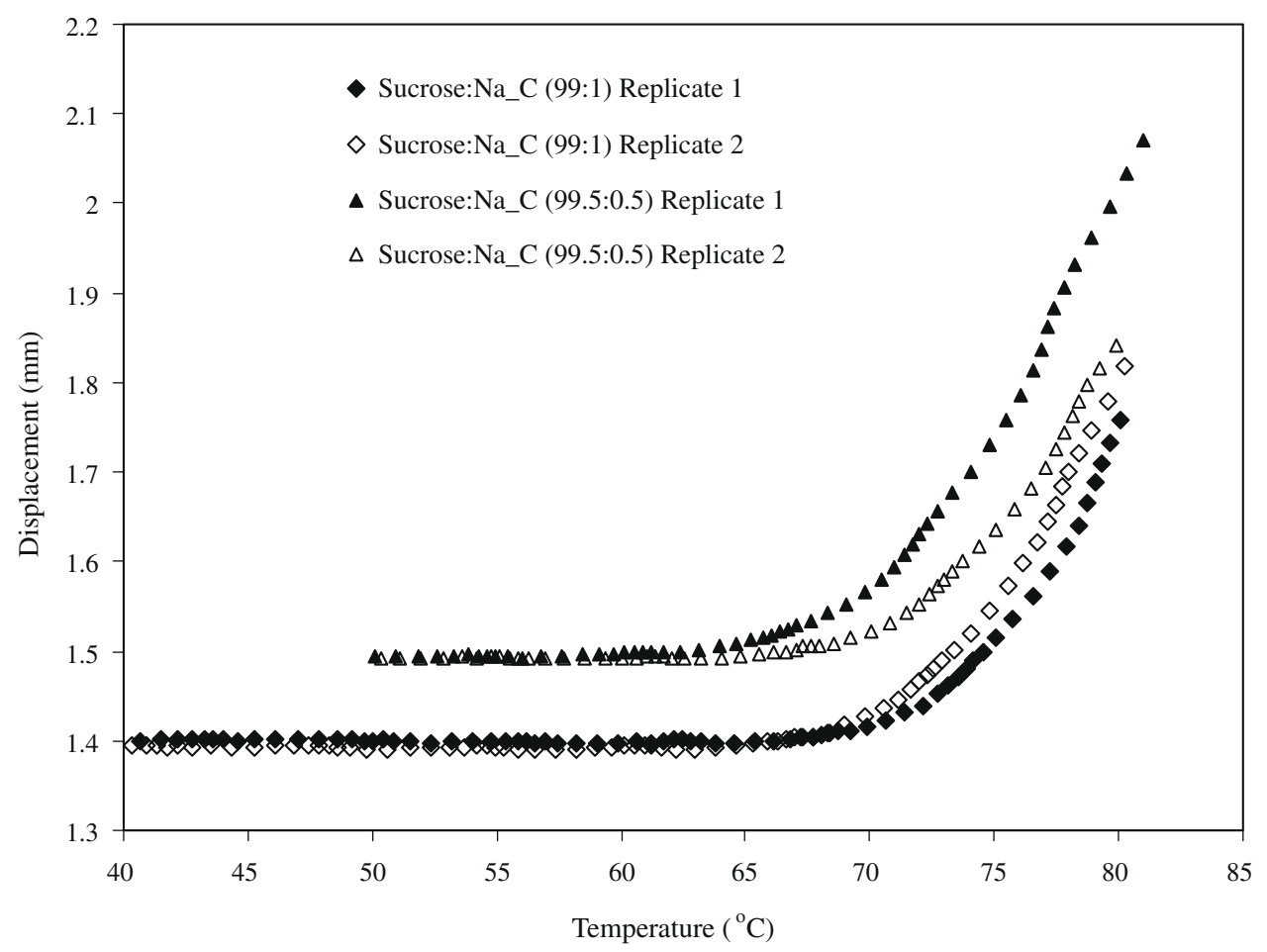

Fig. 6. A typical example of data fitting to determine the $T_{\mathrm{g}}$ by tracking the intersection of two straight lines.

Table 4

Experimental $T_{\mathrm{g}}$ values of spray dried sucrose-Na-C and sucrose-WPI powders along with the predicted bulk $T_{\mathrm{g}}$ and $T_{\mathrm{g}, \text { surface layer }}$ values.

\begin{tabular}{|c|c|c|c|c|}
\hline Samples & Moisture (g water/100 g solids) & $T_{\mathrm{g} \mathrm{r}}$ (experimental) (bulk) $\left({ }^{\circ} \mathrm{C}\right)$ & $T_{\mathrm{g}}$ (predicted) (bulk) $\left({ }^{\circ} \mathrm{C}\right)$ & $T_{\mathrm{g}}$ (predicted) (surface layer) $\left({ }^{\circ} \mathrm{C}\right)$ \\
\hline \multirow{4}{*}{ Sucrose:Na-C (99:1) } & $0 \pm 00$ & $70.97 \pm 0.77$ & 65.70 & 104.03 \\
\hline & $1.52 \pm 0.10$ & $59.7 \pm 0.83$ & 52.79 & 81.09 \\
\hline & $2.60 \pm 0.09$ & $52.07 \pm 0.57$ & 44.59 & 67.44 \\
\hline & $2.81 \pm 0.32$ & $51.66 \pm 0.47$ & 43.08 & 65.00 \\
\hline \multirow[t]{4}{*}{ Sucrose:Na-C (99.5:0.5) } & $0 \pm 00$ & $69.9 \pm 0.89$ & 65.35 & 100.36 \\
\hline & $1.07 \pm 0.06$ & $59.7 \pm 0.89$ & 56.15 & 84.41 \\
\hline & $2.64 \pm 0.15$ & $52.12 \pm 0.4$ & 44.10 & 64.80 \\
\hline & $2.78 \pm 0.10$ & $51.92 \pm 0.46$ & 43.10 & 63.23 \\
\hline \multirow[t]{4}{*}{ Sucrose:WPI (99:1) } & $0 \pm 00$ & $67.24 \pm 93$ & 65.88 & 116.44 \\
\hline & $1.33 \pm 0.09$ & $53.07 \pm 0.69$ & 54.07 & 87.61 \\
\hline & $1.99 \pm 0.04$ & $51.85 \pm 1.38$ & 48.90 & 75.90 \\
\hline & $2.16 \pm 0.04$ & $51.62 \pm 1.22$ & 47.61 & 73.11 \\
\hline \multirow[t]{4}{*}{ Sucrose:WPI (99.5:0.5) } & $0 \pm 00$ & $66.37 \pm 0.80$ & 65.44 & 114.74 \\
\hline & $1.00 \pm 0.07$ & $59.83 \pm 2.29$ & 57.09 & 92.80 \\
\hline & $1.92 \pm 0.06$ & $49.3 \pm 0.37$ & 49.67 & 76.15 \\
\hline & $2.12 \pm 0.11$ & $45.73 \pm 0.47$ & 48.13 & 72.89 \\
\hline
\end{tabular}


ing and spray drying. Powders of lactose:Na $\mathrm{C}$ and lactose:WPI with solid ratios of $(5: 1)$ and (3:1) were produced through spray drying and freeze drying. The $K$ value for Gordon Taylor equation (Eq. (1)) for the lactose:Na C (3:1) and lactose WPI (3:1) were found to be 7.2 and 8.1 , respectively which provide the moisture dependence of the $T_{\mathrm{g}}$. From the knowledge of $T_{\mathrm{g}}$ and $K$ values of lactose which are $105.4{ }^{\circ} \mathrm{C}$ and $6.9{ }^{\circ} \mathrm{C}$, respectively both the anhy drous $T_{\mathrm{g}}$ of Na $\mathrm{C}$ and WPI along with their moisture dependence $\left(K_{\mathrm{Na}-\mathrm{C}-\mathrm{w}}\right.$ and $\left.K_{\mathrm{WPI}-\mathrm{w}}\right)$ can be determined. $T_{\mathrm{g}}$ values of $\mathrm{Na} \mathrm{C}$ and WPI were calculated to be $135^{\circ} \mathrm{C}$ and $153^{\circ} \mathrm{C}$, respectively. These values agree well with $T_{\mathrm{g}}$ of $140{ }^{\circ} \mathrm{C}$ reported by Kalichevsky et al. (1993) for Na C and $153^{\circ} \mathrm{C}$ for WPI reported by Matveev et al. (1997). We calculated the water dependence of for Na C $\left(K_{\mathrm{Na}-\mathrm{C}-\mathrm{w}}\right)$ and WPI $K_{\mathrm{WPI}-\mathrm{w}}$ ) be 8.55 and 12.60 , respectively. These $K$ values indicate that water will have quite strong plasticization effect on both the Na C and WPI.

$T_{g, \text { solid water }} \frac{x_{\mathrm{s}} T_{\mathrm{g}, \mathrm{s}}+x_{\mathrm{w}} K_{\mathrm{s}, \mathrm{w}} T_{\mathrm{g}, \mathrm{w}}}{x_{\mathrm{s}}+x_{\mathrm{w}} K_{\mathrm{s}, \mathrm{w}}}$

$T_{\mathrm{g} \text {, solid-water }}$ is the glass transition temperature of a solid water bin ary mixture, $x_{\mathrm{s}}$ and $x_{\mathrm{w}}$, respectively, are the mass fraction of solid and water in the solution. $T_{\mathrm{g}, \mathrm{s}}$ is the $T_{\mathrm{g}}$ of anhydrous solid, $T_{\mathrm{g}, \mathrm{w}}$ is the $T_{\mathrm{g}}$ of pure water. The constant $K_{\mathrm{s}, \mathrm{w}}$ is a dimensionless propor tionality constant that provides the moisture dependence of the $T_{\mathrm{g}}$.

We calculated the $T_{\mathrm{g}}$ of multi component mixtures using a mass weighted mean rule. First, the multi component mixture is as sumed to be composed of $n$ individual binary solid water mixtures, where $n$ is the number of solid components. The moisture depen dence of $T_{\mathrm{g}}$ for each binary solid water mixture is then determined using Eq. (1) and known $K_{\text {solid-water }}$ values. Finally, the solids are as sumed to be uniformly mixed and the $T_{\mathrm{g}}$ of the multi component mixture is computed as a mass weighted mean on a water free ba sis as represented by Eqs. (2) and (3).

$T_{g, \text { mixture }} \quad \sum_{i=1}^{n} T_{g, i \mathrm{w}} x_{\mathrm{i}}$

$\sum_{i=1}^{n} x_{\mathrm{i}}$

$T_{\mathrm{g}, \mathrm{mixt}}$ is the $T_{\mathrm{g}}$ of the multi component mixture including water. $T_{\mathrm{g}, \mathrm{i}-\mathrm{w}}$, represents the $T_{\mathrm{g}}$ of binary solid water mixtures such as: sucrose water $\left(T_{\mathrm{g}, \mathrm{s}-\mathrm{w}}\right)$, WPI water $\left(T_{\mathrm{g}, \mathrm{WPI}-\mathrm{w}}\right)$ and so on. $x_{\mathrm{i}}$ is the fraction of an individual solid component on a water free solids ba sis. In Eq. (2) the effect of water (plasticizer) has already been incorporated through the $T_{\mathrm{g}}$ relationship for each binary solid water mixture. The $T_{\mathrm{g}}$ and $K_{\text {solid-water }}$ values for the pure samples are listed in Table 5.

The experimental $T_{\mathrm{g}-\mathrm{r}}$ and predicted $T_{\mathrm{g}}$ values for the test sam ples at various moisture contents are presented in Table 4. It can be seen from this table that the maximum difference in prediction in case of sucrose:Na $\mathrm{C}$ and sucrose:WPI powders is $5^{\circ} \mathrm{C}$ and $3{ }^{\circ} \mathrm{C}$, respectively. This agreement in predicted and experimental values indicates towards two facts, firstly, the TMCT is able to measure, quite accurately, the glass rubber transition of the sugar protein system and also that at prevailing concentration of sucrose in these

Table 5

Glass transition temperature $\left(T_{\mathrm{g}}\right)$ and water dependence $\left(K_{\text {solid water }}\right)$ of sample materials.

\begin{tabular}{lll}
\hline Samples & $T_{\mathrm{g}}\left({ }^{\circ} \mathrm{C}\right)$ & $K_{\text {solid water }}$ \\
\hline Water & -135 & - \\
Sucrose & 65 & 4.47 \\
Na-C & 135 & 8.55 \\
WPI & 153 & 12.60 \\
\hline
\end{tabular}

powders, the protein is unable to raise the bulk $T_{\mathrm{g}}$ of these powders.

We also calculated the value for the glass transition tempera ture of the powder surface layer, $T_{\mathrm{g}, \text { surface layer }}$. This calculation is based on the ESCA results, as described in Section 3.2.1. There is no way to accurately predict the thickness of this surface layer. As the incident $X$ ray only penetrates $1020 \mathrm{~nm}$ into the particle surface, the value obtained for $T_{\mathrm{g}, \text { surface layer }}$, will be a measure of the glass transition temperature within this layer assuming that the moisture has had time to diffuse through the powder. Finally, Eqs. (1) (3) were used to predict the $T_{\mathrm{g}, \text { surface layer }}$ and the results are presented against their moisture content in Table 4 . It can be seen from this table that the $T_{\mathrm{g}, \text { surface layer }}$ values of these powders are $2040{ }^{\circ} \mathrm{C}$ higher than their corresponding bulk $T_{\mathrm{g}}$ values. Fur thermore, the $T_{\mathrm{g}, \text { surface layer }}$ values are close to or greater than the outlet temperature of the dryer. Assuming that the sticky point temperature exceeds the surface layer glass transition temperature by $20^{\circ} \mathrm{C}$, at the prevailing drying conditions, the particle tempera tures have always remained within the safe drying regime for the sucrose:protein powders.

The extraordinary behaviour of Na C and WPI to raise the recovery of sucrose powder from zero to greater than $80 \%$ in spray drying trials (Table 1 ) and to convert it into a fully amorphous powder (Fig. 2) has been possible due to two reasons. Firstly, these proteins preferentially migrate to the air water interface driven by their surface activity. There they form a very thin protein rich film. When these droplets are subjected to convective dying environ ment in the spray dryers, very rapid glassy film formation takes place (Fig. 4). $0.125 \%$ (on a nominal feed basis) protein in droplet is sufficient to provide maximum driving force (lowered surface tension), for maximum surface coverage, this amount of protein is sufficient to overcome the stickiness and hence to raise the pow der recovery to greater than $80 \%$. Doubling of the feed protein con centration was found to have little effect on either the surface tension of the feed solution, or the recovery obtained in the spray dryer. Furthermore, the ability of protein film to convert into glassy state at much higher mean moisture content than that of malto dedextrin DE6 (Fig. 4) and to raise the $T_{\mathrm{g}, \text { surface layer }}$ explains why protein can act as smart drying aids. Furthermore, since maltodext rins are not surface active, they will have much reduced ability to preferentially cover the surface of the droplets during the particle formation process.

\section{Conclusions}

We produced amorphous sucrose powder through spray drying trials. $0.51 \%$ sodium caseinate and Whey Protein Isolate on a dry solid basis were added to sucrose and spray dried with inlet and outlet temperatures of $160{ }^{\circ} \mathrm{C}$ and $70{ }^{\circ} \mathrm{C}$, respectively. This amount of protein addition was sufficient to convert the crystalline sucrose (first converting it into aqueous solution) into amorphous form. The recovery of powder was also increased from $0 \%$ of pure sucrose to greater than $80 \%$ in the presence of these proteins. This is attrib uted to two reasons. Firstly, protein preferentially migrates to the droplet air interface driven by its surface activity. Secondly, it forms a thin protein rich film soon after coming in contact with drying air. The film converts into glassy state and acts to overcome both the particle to particle and particle to wall stickiness by rais ing the glass transition temperature of the surface layer.

\section{Acknowledgements}

The authors acknowledge Mr Tai Chong, Lee and Miss Ewe Ai Ting for their help in experiments. This work was supported by the Australian Research Council's Discovery Grant Scheme. 


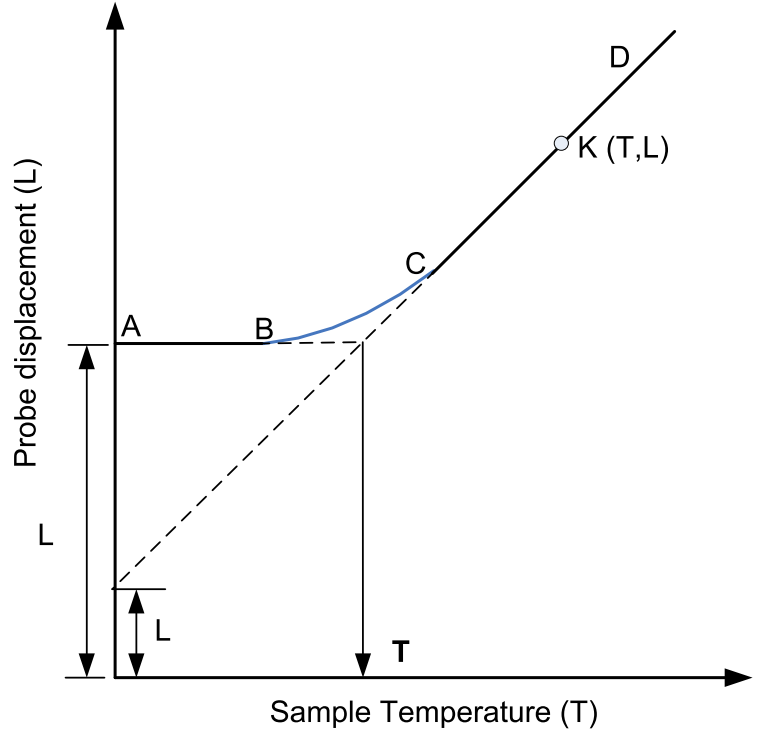

Fig. 7. A typical probe displacement versus temperature curve in TMCT (for Appendix A).

\section{Appendix A. An algorithm to fit the experimental sample temperature versus probe displacement data points to calculated $\boldsymbol{T}_{\mathrm{g}-\mathrm{r}}$}

Equation of any point $K(T, L)$ on the CD straight line in Fig. 7 is given by

$L=L^{\prime}+C_{2} T$

where, $C_{2}$ is the slope of the $C D$ straight line and $T$ is the sample temperature. However, the intercept $L^{\prime}$ is a part of $L_{\mathrm{Tg}, \mathrm{r}}$ which is the intercept of the straight line $\mathrm{AB}$. Hence,

$L_{\mathrm{Tg}-\mathrm{r}}=L^{\prime}+C_{2} T_{\mathrm{g}-\mathrm{r}}$

$T_{\mathrm{g}-\mathrm{r}}$ is the glass-rubber transition temperature. It is assumed here that the slope of the line $A B$ is zero. The $T_{\mathrm{g}-\mathrm{r}}$ lies on the extrapolated section of the line $A B$.

From (A2),

$L^{\prime}=L_{\mathrm{Tg}-\mathrm{r}}-C_{2} T_{\mathrm{g}-\mathrm{r}}$

From (A1) and (A3)

$L=L_{\mathrm{Tg}-\mathrm{r}}-C_{2} T_{\mathrm{g}-\mathrm{r}}+C_{2} T$

In spread sheet format an algorithm is written to fit the experimental data points as given by Eqs. (A5), (A6) below.

If $T<T_{\mathrm{g}-\mathrm{r}}$, then $L=L_{\mathrm{Tg}-\mathrm{r}}$

If $T>T_{\mathrm{g}-\mathrm{r}}$ then $L=L_{\mathrm{Tg}-\mathrm{r}}-C_{2} T_{\mathrm{g}-\mathrm{r}}+C_{2} T$

\section{References}

Adhikari, B., Howes, T., Shrestha, A.K., Bhandari, B.R., 2007. Development of stickiness of whey protein isolate and lactose droplets during convective drying. Chemical Engineering and Processing 46 (5), 420-428.

Bhandari, B.R., Datta, N., Crooks, R., Howes, T., Bhandari, B.R., 1997. A semi-empirical approach to optimise the quantity of drying aids required to spray dry sugarrich foods. Drying Technology 15 (10), 2509-2525.

Boonyai, P., Bhandari, B., Howes, T., 2006. Applications of thermal mechanical compression tests in food powder analysis. International Journal of Food Properties 9 (1), 127-134.

Bos, M.A., van Vliet, T., 2001. Interfacial rheological properties of adsorbed protein layers and surfactants: a review. Advances in Colloid and Interface Science 91, 437-471.

Ciz, K., 1973. Use of starch for preventing agglomeration of icing sugar. Industries Alimntaires et Agricoles 90 (7-8), 969-972.

Faldt, P., Bergenstahl, B., Carlsson, G., 1993. Surface coverage of fat on food powders analyzed by ESCA(Electron-Spectroscopy for Chemical-Analysis). Food Structure 12 (2), 225-234.

Haque, M.K., Roos, Y.H., 2006. Differences in the physical state and thermal behavior of spray-dried and freeze-dried lactose and lactose/protein mixtures. Innovative Food Science and Emerging Technologies 7 (1-2), 62-73.

Haque, M.K., Roos, Y.H., 2004. Water sorption and plasticization behavior of spraydried lactose/protein mixtures. Journal of Food Science 69 (8), E384-E391.

Kalichevsky, M.T., Blanshard, J.M.V., Tokarczuk, P.F., 1993. Effect of water-content and sugars on the glass-transition of casein and sodium caseinate. International Journal of Food Science and Technology 28 (2), 139-151.

Kim, E.H.J., Chen, X.D., Pearce, D., 2002. Surface characterization of four industrial spray-dried dairy powders in relation to chemical composition, structure and wetting property. Colloids and Surfaces B-Biointerfaces 26 (3), 197-212.

Krishnamurthy, R., Suryanarayanan, R., 2006. Improved Process for Preparing a Freeze Dried Formulation Comprising Protein Active Agent, Saccharide Stabilizing Agent and Bulking Agent, Comprises Using Freezing Conditions Sufficient to Maintain the Bulking Agent in an Amorphous State. World Patent (WO 2006014965-A2).

Matveev, Y.I., Grinberb, V.Y., Sochava, I.V., Tolstoguzov, V.B., 1997. Glass transition temperature of proteins. Calculation based on the additive contribution method and experimental data. Food Hydrocolloids 11 (2), 125-133.

Roos, Y.H., 1993. Melting and glass transitions of low-molecular-weight carbohydrates. Carbohydrate Research 238, 39-48.

Roth, D., 1977. The agglomeration behaviour of freshly milled sugar. Zucker 30 (9), 464-470.

Rowe, R.C., Sheskey, P.J., Owen, S.C., 2006. Handbook of Pharmaceutical Excipients, fifth ed. Pharmaceutical Press, American Pharmacists Association, Washington, DC.

Sapronov, A.R, Slavyanskii, A.A., Zhigalov, M.S., 1995. Preparation of Icing Sugar Comprises Drying Crystals, Mixing With Potato Starch, Grinding, Separating into Fractions, Mixing With Maize Starch, etc. Russian Patent (RU2046148-C1).

Shrestha, A.K., Ua-Arak, T., Adhikari, B.P., Howes, T., Bhandari, B.R., 2007a. Glass transition behavior of spray dried orange juice powder measured by differential scanning calorimetry (DSC) and thermal mechanical compression test (TMCT). International Journal of Food Properties 10 (3), 661-673.

Shrestha, A.K., Howes, T., Adhikari, B.P., Bhandari, B.R., 2007b. Effect of protein concentration on the surface composition, water sorption and glass transition temperature of spray-dried skim milk powders. Food Chemistry 104 (4), 14361444.

Svolos, T., 1971. Hydrocolloids as icing stabilizers. Bakers' Digest 45 (3), 57-61.

Tarasov, V.V., Kovalenko, N.F., Shcherbakova, G.S., Zhang, D., 2006. Linear and radial marangoni flows of surfactants. Theoretical Foundations of Chemical Engineering 40 (2), 111-115.

Truong, V., Bhandari, B.R., Howes, T., 2005. Optimization of cocurrent spray drying process for sugar-rich foods. Part II - optimization of spray drying process based on glass transition concept. Journal of Food Engineering 71 (1), 66-72.

Vega, C., Roos, Y.H., 2007. The state of aggregation of casein affects the storage stability of amorphous sucrose, lactose and their mixtures. Food Biophysics 2 (1), 10-19.

Vega, C., Goff, H.D., Roos, Y.H., 2005. Spray drying of high-sucrose dairy emulsions: feasibility and physicochemical properties. Journal of Food Science 70 (3), E244-E251.

Weast, R.C., 1988. CRC Handbook of Chemistry and Physics, student ed. CRC Press, Boca Raton, FL. 